\title{
RESEARCH ON THE PHYSIQUE OF THE ATHLETES PARTICIPATING IN THE NATIONAL ATHLETIC MEETINGS
}

\author{
Research Committee of the \\ National Athletic Meeting \\ of Japan
}

(Chairman: Toshiro AZUMA,)

\section{Motives and aims}

The National Athletic Meeting, aiming at the revival of sports and the elevation of the physical standard of the people after the war, was first held in 1946, sponsored by the Japan Amateur Sports Association and it has since been held annually. Recognizing the necessity for supervising the athletes' health so as to promote the sound development of sports, it has decided, as one measure, since its fourth meeting (1949) that every participating athletes must attach a physical examination certificate (later changed to health certificate) to their application forms. These certificates have been collected at the medical division of the Association through the different groups classified according to the events at each meeting, for more than ten years, while the medical division, using them for data, has presented to the Japanese Physical Fitness Society "A Statistical Observation on the Physical Examination of the Athletes in the Fifth, Seventh, Eighth and Nineth National Athletic Meetings".

As the decision that the next Olympics should be held in Tokyo, and the year-by-year growth of the National Athletic Meetings have served as strong incentives to the development of sports in Japan, the necessity has been keenly felt of investigating into the past data to be utilized for further development, and the significance has been realized of learning about the characteristics of the Japanese athletes' physique according to the various events they are trained for and its changes during the last fourteen or fifteen years. Hence this research has been started.

Its aims are to know the physical status of Japanese athletes by investigating into the physical conditions of the athletes who have participated in the National Athletic Meetings of the last ten years, as classified by events, age, sex and year of participation, and therewith contribute to the future development of sports in Japan, and also to make health supervision for the athletes more effective in future.

\section{Objects and items for investigation}

This investigation was made, with the participation of athletes in various events using the 
physical examination certificates annually presented by them since 1949 .

Using the collected physical examination certificates, the following items were inquired into:

a) Stature, weight and the girth of chest: drawing up of the frequency distribution charts for each year according to events, sex and age groups, and working out their arithmetic means and standard deviation.

b) The number of the entries for all the events: drawing up age distribution charts for the Fourth, Seventh, Tenth and Thirteenth Meetings.

c) Comparison of the physique of the athletes of a respective age in every event in the latest years with the national standard.

d) Each event: examination of the status of physical growth and changes during the last ten years.

e) Investigation, by prefectures, of the number of participants in every year and event.

f) Occupational census of participating athletes.

g) Investigation of the vital capacity, menstruation, and so on, by event groups.

h) Investigation by event groups of the trend of the physique in a respective age group.

i) Improving the existing physical examination certificate form.

\section{Personnel stiucture of the athletes}

(1) The number of the participants

The number of the participants (including the staff) from the Fourth to the Tenth Meeting amounts to 169,367 , averaging 16,936 per year. The difference in the number of each year has been caused by the fact that the number of participants was restricted by various conditions, such as traffic, sports facilities, lodging accommodations and the budget of the districts.

(2) The personnel by sex and age

The youngest of all the men and the women were both fifteen years of age. The oldest of all the men and the women were respectively in his sixties and in her forties. Seventeen years old of both sexes far outnumber the rest in each year.

\section{The methods of investigation}

(1) The plans of investigation

This kind of research requires careful plans to be worked out in the collection and arrangement, management, statistical analysis, etc. of data. The medical division of the Japan Amateur Sports Association and twenty-two specialists in sports medicine, health and physical education, and statistics from six voluntary universities in Tokyo organized the above mentioned Committee; this committee conducted the research.

The main objects for investigation (chiefly about the physique) are as follows:

a. As a basic measure, to make frequency distribution charts with respect to stature, weight, the girth of chest and vital capacity of the athletes by sex, age and event in each meeting from the Fourth to the Thirteenth, and work out the maximum, the minimum, the 
arithmetic mean ( $\overline{\mathbf{x}})$ and the standard deviation (s) in each chart.

b. As for the Fourth, Seventh, Tenth, Thirteenth Meetings to compare the mean of the stature, weight, and the girth of chest in the respective age groups of each event with that of the whole country and examine the difference.

From these we made up charts for comparing the average of each event (by sex) of the respective ages (chiefly seventeen, and twenty...... twenty-four years of age) at every meeting (the Fourth, Seventh, Tenth, Thirteenth) with the national average.

(2) Arrangement and adding up of the data.

The data for this research are the physical examination certificates which have been presented with the application forms by the athletes, sent to the medical division of the Japan Amateur Sports Association, through each event group. The total number is 48,536, and its rate of collection is 37.5 per cent.

Incomplete statements were excluded, the data were arranged and classified by age groups, and then frequency distribution charts were drawn up, for each of which the means $(\overline{\mathbf{x}})$ and the standard deviations (s) were calculated.

(3) Statistical analysis

Thus the average of stature, weight, the girth of chest and vital capacity by sex and age groups in each event could be known; but for statistical analysis we made a comparative study of the averages of stature, weight, and the girth of chest with those of the whole nation, using a significance test. By this the characteristics of the physique by event groups may be grasped.

Note: The sources for the national average:

15 17 years of age...... The average of those for high-school students according to the Reports on the Statistics of School Health Examination by the Ministry of Education.

18 24 years of age..... The average of those for university students according to the Reports on the Statistics of School Health Examination by the Ministry of Education.

above 25 years of age $\cdots$ National Physique Statistics according to the survey on the national nutritional conditions by the Ministry of Health and Welfare.

\section{The result of the investigation}

As a result of this investigation, concerning the physique of the athletes, we were able to obtain the respective averages of stature, weight, the girth of chest, and vital capacity by events (thirty-two in all), sex, age groups, at each of the meetings from the Fourth to the Thirteenth; also for statistical analysis we made a comparative study with a significance test between the averages of the Fourth, Seventh, Tenth, and Thirteenth Meeting and the above mentioned national averages in the main age group (seventeen years of age). In our report this time, we selected the following events and examined the changes of the physique of the 
athletes who have participated in the National Athletic Meeting, the greatest sports event in this country. (See Table)

The selected events :

Male......volley-ball, soccer, gymnastics, swimming, Sumo.

Female $\cdots$ handball, gymnastics.

The reason for choosing the age group seventeen is that, as mentioned before, the number of the personnel of this age is the largest; that is, seventeen is the mode, in almost all the events. The reason for selecting the above events is that the physical examination certificates of the athletes of seventeen years of age participating in these events are fairly well arranged. The fact that these events are relatively universal throughout the country is also another reason.

As for ball games, the general tendency common to all the Meetings is as follows:

In the age group of seventeen, the averages of weight, stature, and the girth of chest of those participating in volley-ball and soccer are singificantly above those of the whole nation. In volley-ball the averages of stature, weight and the girth of chest are significantly above the national averages at every meeting. However, in soccer, the average stature is above the national average, but with little difference, and only the averages of weight and the girth of chest are significantly above.

The participants of gymnastic exercises present a unique type; that is, the average stature, in most cases, is significantly below, the average weight is significantly above, and the average the girth of chest is significantly above the national average.

In swimming, the average stature, weight and the girth of chest are significantly above the national ones.

In the special sport, Sumo, as in the case of swimming, the average stature, weight and girth of chest are significantly above the national ones.

As for women, the average stature, weight and chest of the participants in handball are significantly above the national ones.

In gymnastic exercises, the average stature, weight and the girth of chest vary at each meeting.

These findings are interesting results as they indicate similarities in the types of the physique of sportsmen.

It must not be forgotten however, that the results of our investigation merely show things as they are, and that whether the physique has really improved or not through sports can not be determined with this sort of materials only. These points will be worth further examination.

Among ball games, the good physique of the athletes in soocer, which is called heavy athletics, is easily understood, but the excellence of the physique in volley-ball seems to prove the fact that improvement in physique and health can be attained by the adoptation of the adequate dosis of exercise not only in school physical education but also in the daily lives of people in industries and of the general public. 
Table 1. Comparison of physique of athletes who participated in the National Athletic Meetings and average Japanese. (1949 1958, Age 17 and 20 24).

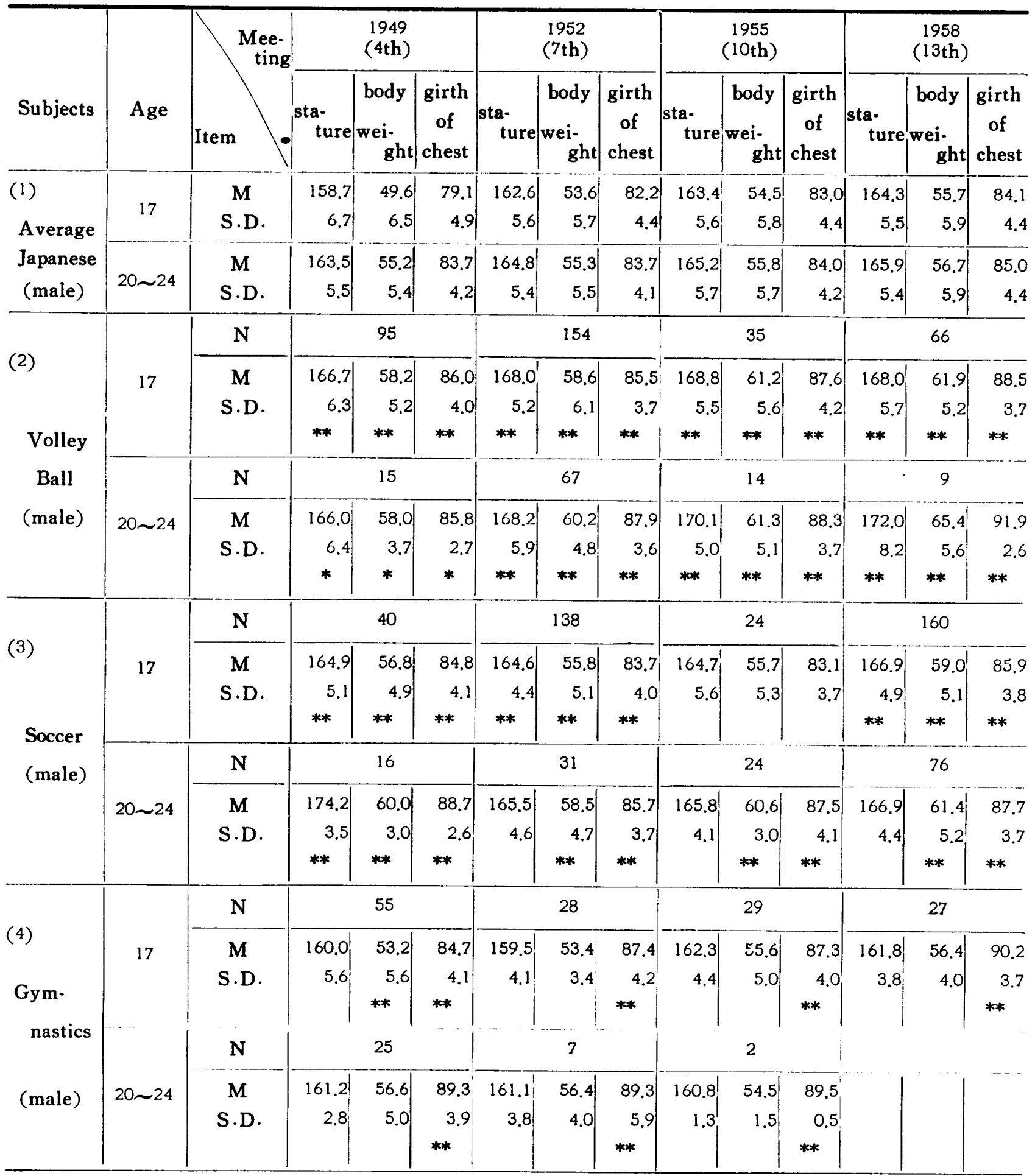

Note: $\mathrm{N}$ : Number of subject

$M$ : Mean value

S.D. : Standard deviation
Significance P $1 \%$

* Significance P 5\% 


\begin{tabular}{|c|c|c|c|c|c|c|c|c|c|c|c|c|c|c|}
\hline \multirow[b]{2}{*}{ Swim- } & \multirow[b]{2}{*}{17} & $\mathbf{N}$ & & & & \multicolumn{3}{|c|}{83} & \multicolumn{3}{|c|}{82} & \multicolumn{3}{|c|}{115} \\
\hline & & $\begin{array}{c}\text { M } \\
\text { S.D. }\end{array}$ & & & & $\begin{array}{r}167.0 \\
4.3 \\
* *\end{array}$ & $\begin{array}{r}61.5 \\
5.8 \\
* *\end{array}$ & $\begin{array}{r}89.3 \\
4.1 \\
* *\end{array}$ & $\begin{array}{r}166.9 \\
5.3 \\
* *\end{array}$ & $\begin{array}{r}59.3 \\
5.4 \\
* *\end{array}$ & $\begin{array}{r}88.0 \\
4.6 \\
* *\end{array}$ & $\begin{array}{r}166.9 \\
5.5 \\
* *\end{array}$ & $\begin{array}{c}59.9 \\
6.2 \\
* *\end{array}$ & $\begin{array}{r}91.1 \\
4.4 \\
* *\end{array}$ \\
\hline ming & & $\mathbf{N}$ & & & & \multicolumn{3}{|c|}{81} & \multicolumn{3}{|c|}{71} & \multicolumn{3}{|c|}{86} \\
\hline (male) & $20 \sim 24$ & $\begin{array}{c}\text { M } \\
\text { S.D. }\end{array}$ & & & & $\begin{array}{r}168.7 \\
5.1 \\
* * *\end{array}$ & $\begin{array}{r}61.9 \\
5.5 \\
* *\end{array}$ & $\begin{array}{r}90.5 \\
5.1 \\
* *\end{array}$ & $\begin{array}{r}168.2 \\
4.0 \\
* *\end{array}$ & $\begin{array}{r}60.1 \\
5.6 \\
* *\end{array}$ & $\begin{array}{r}90.6 \\
5.1 \\
* *\end{array}$ & $\begin{array}{r}169.3 \\
4.8 \\
* *\end{array}$ & $\begin{array}{r}64.1 \\
6.6 \\
* *\end{array}$ & $\begin{array}{r}92.1 \\
5.5 \\
* *\end{array}$ \\
\hline \multirow[b]{4}{*}{ (male) } & \multirow[b]{2}{*}{17} & $\mathrm{~N}$ & \multicolumn{3}{|c|}{21} & \multicolumn{3}{|c|}{43} & \multicolumn{3}{|c|}{24} & \multicolumn{3}{|c|}{2} \\
\hline & & $\begin{array}{c}\text { M } \\
\text { S.D. }\end{array}$ & $\begin{array}{r}164.5 \\
5.7 \\
* *\end{array}$ & $\begin{array}{r}66.0 \\
8.5 \\
* *\end{array}$ & $\begin{array}{r}91.5 \\
3.7 \\
* *\end{array}$ & $\begin{array}{c}168.2 \\
4.8 \\
* *\end{array}$ & $\begin{array}{r}67.3 \\
5.1 \\
* *\end{array}$ & $\begin{array}{r}91.9 \\
3.7 \\
* *\end{array}$ & $\begin{array}{r}169.2^{1} \\
6.0 \\
* *\end{array}$ & $\begin{array}{r}71.2 \\
7.5 \\
* *\end{array}$ & $\begin{array}{r}96.0 \\
5.3 \\
* *\end{array}$ & $\begin{array}{r}167.5 \\
3.7\end{array}$ & $\begin{array}{r}70.5 \\
2.0 \\
* *\end{array}$ & $\begin{array}{r}91.5 \\
0 \\
* *\end{array}$ \\
\hline & \multirow[b]{2}{*}{$20 \sim 24$} & $\mathbf{N}$ & \multicolumn{3}{|c|}{43} & \multicolumn{3}{|c|}{29} & \multicolumn{3}{|c|}{16} & \multicolumn{3}{|c|}{23} \\
\hline & & $\begin{array}{c}\text { M } \\
\text { S.D. }\end{array}$ & $\begin{array}{r}169.5 \\
5.1 \\
* *\end{array}$ & $\begin{array}{r}71.3 \\
6.8 \\
* *\end{array}$ & $\begin{array}{r}95.6 \\
4.1 \\
* *\end{array}$ & $\begin{array}{r}170.5 \\
6.3 \\
* *\end{array}$ & $\begin{array}{r}72.7 \\
4.1 \\
* *\end{array}$ & $\begin{array}{r}96.0 \\
2.6 \\
* *\end{array}$ & $\begin{array}{r}168.7 \\
4.3 \\
* *\end{array}$ & $\begin{array}{r}75.7 \\
6.1 \\
* *\end{array}$ & $\begin{array}{r}96.9 \\
4.6 \\
* *\end{array}$ & $\begin{array}{r}172.4 \\
5.3 \\
* *\end{array}$ & $\begin{array}{r}75.9 \\
3.6 \\
* *\end{array}$ & $\begin{array}{r}98.3 \\
5.0 \\
* *\end{array}$ \\
\hline \multirow{3}{*}{$\begin{array}{l}\text { (7) } \\
\text { Average } \\
\text { Japanese } \\
(\text { female })\end{array}$} & 17 & $\mathbf{M}$ & $\begin{array}{r}151.5 \\
5.0\end{array}$ & $\begin{array}{r}47.6 \\
5.5\end{array}$ & $\begin{array}{r}78.5 \\
4.5\end{array}$ & $\begin{array}{r}152.8 \\
4.9\end{array}$ & $\begin{array}{r}49.6 \\
5.3\end{array}$ & $\begin{array}{r}80.0 \\
4.3\end{array}$ & $\begin{array}{r}153.2 \\
4.8\end{array}$ & $\begin{array}{r}49.8 \\
5.7\end{array}$ & $\begin{array}{r}80.5 \\
4.4\end{array}$ & $\begin{array}{r}153.5 \\
4.9\end{array}$ & $\begin{array}{r}50.3 \\
5.5\end{array}$ & $\begin{array}{r}80.7 \\
4.4\end{array}$ \\
\hline & $20 \sim 24$ & $\begin{array}{c}\text { M } \\
\text { S.D. }\end{array}$ & $\begin{array}{r}153.9 \\
5.6 \\
\end{array}$ & $\begin{array}{r}51.2 \\
5.4\end{array}$ & $\begin{array}{r}81.3 \\
4.3 \\
\end{array}$ & $\begin{array}{r}153.7 \\
4.6 \\
\end{array}$ & $\begin{array}{r}49.4 \\
5.1\end{array}$ & $\begin{array}{r}80.6 \\
4.3\end{array}$ & $\begin{array}{r}154.1 \\
5.2\end{array}$ & $\begin{array}{r}49.5 \\
5.2\end{array}$ & $\begin{array}{r}80.8 \\
4.5\end{array}$ & $\begin{array}{r}154.5 \\
4.8\end{array}$ & $\begin{array}{r}49.6 \\
5.5\end{array}$ & $\begin{array}{r}81.0 \\
4.5\end{array}$ \\
\hline & \multirow[b]{2}{*}{17} & $\mathbf{N}$ & \multicolumn{3}{|c|}{17} & \multicolumn{3}{|c|}{48} & \multicolumn{3}{|c|}{28} & \multicolumn{3}{|c|}{38} \\
\hline (8) & & $\begin{array}{c}\text { M } \\
\text { S.D. }\end{array}$ & $\begin{array}{r}154.1 \\
4.8 \\
*\end{array}$ & $\begin{array}{r}51.2 \\
2.6 \\
* *\end{array}$ & $\begin{array}{c}80.3 \\
2.6 \\
*\end{array}$ & $\begin{array}{r}154.2 \\
4.6 \\
*\end{array}$ & $\begin{array}{r}51.3 \\
3.3 \\
*\end{array}$ & $\begin{array}{r}81.0 \\
3.3\end{array}$ & $\begin{array}{r}156.6 \\
3.2 \\
* *\end{array}$ & $\begin{array}{r}54.7 \\
2.8 \\
* *\end{array}$ & $\begin{array}{r}83.0 \\
2.6 \\
* *\end{array}$ & $\begin{array}{r}157.9 \\
3.0 \\
* *\end{array}$ & $\begin{array}{r}57.9 \\
8.5 \\
* *\end{array}$ & $\begin{array}{r}81.4 \\
4.5\end{array}$ \\
\hline \multirow{2}{*}{$\begin{array}{l}\text { Hand } \\
\text { Ball }\end{array}$} & & $\mathbf{N}$ & \multicolumn{3}{|c|}{3} & \multicolumn{3}{|c|}{20} & \multicolumn{3}{|c|}{8} & & 16 & \\
\hline & $20 \sim 24$ & $\begin{array}{c}\text { M } \\
\text { S.D. }\end{array}$ & $\begin{array}{r}153.7 \\
1.5\end{array}$ & $\begin{array}{r}51.0 \\
2.3\end{array}$ & $\begin{array}{r}79.2 \\
0\end{array}$ & $\begin{array}{c}155.4 \\
2.9 \\
*\end{array}$ & $\begin{array}{r}46.2 \\
2.4\end{array}$ & $\begin{array}{r}80.7 \\
2.8\end{array}$ & $\begin{array}{r}162.7 \\
4.5 \\
*\end{array}$ & $\begin{array}{r}51.0 \\
1.2\end{array}$ & $\begin{array}{r}82.5 \\
2.5\end{array}$ & $\begin{array}{r}156.2^{\prime} \\
2.0\end{array}$ & $\begin{array}{r}51.6 \\
2.8 \\
* *\end{array}$ & $\begin{array}{r}85.0 \\
3.5 \\
* *\end{array}$ \\
\hline & & $\mathbf{N}$ & & 50 & & & 14 & & & 18 & & & 37 & \\
\hline Gym- & 17 & $\begin{array}{c}\text { M } \\
\text { S.D. }\end{array}$ & $\begin{array}{c}152.9 \\
3.6 \\
*\end{array}$ & $\begin{array}{c}49.3 \\
3.4 \\
*\end{array}$ & $\begin{array}{r}79.4 \\
3.2\end{array}$ & $\begin{array}{r}151.5 \\
4.5\end{array}$ & $\begin{array}{r}46.8 \\
4.4\end{array}$ & $\begin{array}{r}79.2 \\
4.3\end{array}$ & $\begin{array}{r}154.2 \\
4.1\end{array}$ & $\begin{array}{r}49.4 \\
4.0\end{array}$ & $\begin{array}{c}82.7 \\
3.1 \\
*\end{array}$ & $\begin{array}{r}153.3 \\
3.5\end{array}$ & $\begin{array}{r}50.6 ! \\
3.5\end{array}$ & $\begin{array}{r}82.4 \\
3.2 \\
* *\end{array}$ \\
\hline nastics & & $\mathbf{N}$ & & 25 & & & 10 & & & & & & & \\
\hline (female) & $20 \sim 24$ & $\begin{array}{c}\text { M } \\
\text { S.D. }\end{array}$ & $\begin{array}{r}153.5 \\
2.9\end{array}$ & $\begin{array}{r}50.5 \\
4.9\end{array}$ & $\begin{array}{r}81.3 \\
4.3\end{array}$ & $\begin{array}{r}159.5 \\
1.9\end{array}$ & $\begin{array}{r}51.0 \\
2.5\end{array}$ & $\begin{array}{r}78.5 \\
1.6\end{array}$ & & & & & & \\
\hline
\end{tabular}

Note: $\mathrm{N}$ : Number of subject

$M$ : Mean value

S.D.: Standard deviation
Significance P $1 \%$

* Significance P 5\% 
According to Azuma, Takagaki and Kuroda, even in a group like the Wandervögel, which cannot be included among sports and whose physical average is not significantly above the national one, the average growth of a person during two years is significantly great.1)

Next, surveying the result of the investigation in respect to the changes in physique by event groups during the past ten years from the Fourth to the Thirteenth Meetings, we find the following facts.

As for stature, though the national average has sharply increased between the meeting of 1949 (the Fourth) and that of 1952 (the Fifth) and has steadily increased after that, also, the average stature of the athletes in every event does not always show the same tendency as the national average, some showing a decline (volley-ball and Sumo) and some increasing after a decline (soccer, gymnastics). However, by a comparison of the stature of the participants between the meeting of 1949 (the Fourth) and that of 1958 (the Thirteenth), the tendency to increase can be seen in each event.

As for weight, the national average has increased just as in the case of stature, and the average of the participants in volley-ball and gymnastic exercises also shows a tendency to increase gradually, though in a different degree from the national average. That of participants in soccer, after declining once, has sharply increased at the meeting of 1958 (the Thirteenth). That of Sumo kept increasing up to the meeting of 1955 (the Tenth), but at the meeting of 1958 (the Thirteenth) it shows a decline, though slight. That of swimming declined once and then increased, but it is still below that of 1952 (the Seventh). By a comparison between the meetings of 1949 (the Fourth) and of 1958 (the Thirteenth), it has been proved that the average of each event, except swimming, has increased.

As for the girth of chest, the national average shows a similar tendency to increase as in those of stature and weight, but the averages of the athletes in some events have increased and then declined (Sumo), in some others have decreased and then increased (volley-ball, soccer, swimming), and in still others have shown a general tendency to increase (gymnastic exercise). Comparing the meeting of 1958 (the Thirteenth) with that of 1949 (the Fourth), we can see that in every event the average has increased. (Only, that of Sumo remains the same.)

As for women, the national averages of stature, weight, and the girth of chest have shown a very similar tendency to increase as those of men.

As for stature, the average of participants in handball has sharply increased since the meeting of 1952 (the Seventh), but of those in gymnastic exercises a tendency to increase and to decrease have alternately been seen.

As for weight, the average of participants in handball has increased as in the case of stature, and in gymnastic exercises it once declined and then has increased.

As for the girth of chest, the average of participants in handball kept increasing up to the meeting of 1955 (the Tenth) and decreased at the meeting of 1958 (the Thirteenth). In gymnastic exercises it slightly decreased, then sharply increased and again slightly declined.

In the case of women, also, a comparison between the meetings of 1949 (the Fourth) and 
1958 (the Thirteenth), shows that each average in every event has increased as those of men.

These data are in no case sufficient for us to measure the changes in the physique of participants at every meeting, but the fact that the physique of the whole nation and also that of the athletes have been improving may be easily guessed from these data.

\section{Summary}

After arranging and totaling the physical examination certificates and carrying on a research with these as materials, we felt the following things.

1. As the number of the certificates vary greatly with the years and the events, we had trouble in making out the total. This seems to owe in part to the lack of understanding of the certificates on the part of the people concerned in the meetings at different localities and the staff members of athletic organizations, and also in part to the failure in utilizing the certificates submitted. It is encouraging, however, that since the first report was published in 1960, the certificates have come to receive better attention among the above mentioned persons concerned and the athletes, and also to gain more accuracy year by year.

2. The certificates are very important materials to know the physical conditions of the athletes of this country. Therefore, the result of this research offers significant reference data not only to the Japanese sports circles but also to the scholarly circles of physical education. So further accuracy of their contents should be aimed at. Moreover, to get a high collection rate of the certificates is one of the important things for making this research profitable, and for this purpose it is essential that the participating athletes should have a correct understanding for the writings and submitting of them.

3. Among the athletes of the National Athletic Meetings, those who have participated in it consecutively for more than ten years number over fifty. Thinking that by learning about the course of the physical development of these athletes we might get very useful materials which will surely contribute to the development of sports, we tried to investigate it, but we have found that many of them have not always presented their health certificates. Thus we could not hope to reach any conclusion; we had to leave it for the future.

The members who engaged in this research are as follows:

Toshiro Azuma (Chairman), Shiro Mizumachi, Yoshio Kuroda, Katsuya Suzuki,

Haruo Takazawa. (Japan Amateur Sports Association)

Rokuro Sasahara, Sadao Izumi, Junji Tanaka, Takahisa Yamamoto.

(University of Tokyo)

Hiroshi Ejiri, Sanshiro Oishi, Kazui Abe, Terumi Mori. (Tokyo University of Education)

Shiro Seki, Takamitsu Fukunishi, Yoshio Hatori. (Tokyo Gakugei University)

Toichiro Takagaki, Sadao Saito. (Juntendo University)

Misao Miyazaki, Yasuji Inagaki. (Japan Physical Education College) 
Kiyoshi Yoshida (Vice-chairman), Toshitaka Inoue, Kosuke Sugimoto. (Nihon University,)

This papar was prepared by Takahisa Yamamoto, University of Tokyo, summarizing the original report published by the Japan Amateur Sports Association in 1961.

\section{Reference}

1) Auzma, Takagaki and Kuroda: The Physique of Athletes in Various Sports: Significance Tests and Multiple Correlations in Physical Fitness Statistics. Journal of the Physical Education Dept. of Juntendo University, Vol. 1, 1958. 